\title{
Dynamic properties of reactor steels Kh16N15M3T1 and Kh13V2 under shock-wave loading of submicrosecond scale
}

\author{
Sergey S. Mokrushin ${ }^{1}$, Anna S. Mayorova ${ }^{1}$, Svetlana N. Malyugina ${ }^{1}$, Alexander V. Pavlenko ${ }^{1, \mathrm{a}}$, Victor V. Sagaradze ${ }^{2}$, \\ Natalya $V$. Kataeva ${ }^{2}$, Elena $G$. Volkova ${ }^{2}$ \\ ${ }^{1}$ RFNC-VNIITF, Snezhinsk, Russia \\ ${ }^{2}$ Institute of Metal Physics, Ural Branch of Russian Academy of Sciences

\begin{abstract}
Kh16N15M3T1 and Kh13V2 reactor steels were investigated. The study was carried out using a light-gas gun with the deformation velocities ranging from $4 \cdot 10^{4}$ to $3 \cdot 10^{6} \mathrm{~s}^{-1}$ and shock-loading pulses in 0.05 $1 \mu$ s duration range. Dependences of the spallation strength and dynamic elastic limit in a wide temperature range are obtained. The recovered specimens were used to carry out the metallography analysis.
\end{abstract}

\section{Introduction}

The available works does not provide any data associated with Kh16N15M3T1 and Kh13V2 steels' strength properties and deformation mechanisms so this work is aimed at investigating into the properties and deformation mechanisms of these steels. These materials being new and promising are of particular interest to nuclear power engineering. The work consists of two parts. The team from RFNC-VNIITF laboratory used a light-gas gun to study the dynamic properties and concurrently record the obtained data by VISAR and PDV interferometers. The Institute of Metal Physics Ural branch of Russian Academy of Sciences used the recovered specimens to carry out the metallography analysis.

\section{Properties and chemical composition of steels}

Kh16N15M3T1 alloy is what is known as austenitic steel. Table 1 shows the steel chemical composition (wt. $\%)$

Table 1. Kh16N15M3T1 steel chemical composition.

\begin{tabular}{|c|c|c|c|c|}
\hline${ }_{24} \mathrm{Cr}$ & ${ }_{28} \mathrm{Ni}$ & ${ }_{42} \mathrm{Mo}$ & ${ }_{22} \mathrm{Ti}$ & ${ }_{12} \mathrm{C}$ \\
\hline 15.9 & 15 & 2.5 & 1.02 & 0.03 \\
\hline
\end{tabular}

The initial structure of steel quenched from $1100^{\circ} \mathrm{C}$ is introduced by polyhedral austenitic grains sized 20$40 \mu \mathrm{m}$ (figure 1) and low density of dislocations (less than $\left.10^{8} \mathrm{~cm}^{-2}\right)$. The grains have quite a stable FCC lattice.

The steel features a low degree of irradiationinduced swelling (about $0.6 \%$ ) under fast neutron irradiation in $\mathrm{BN}-600$ reactor in the temperature range of maximum swelling rate from 480 to $500{ }^{\circ} \mathrm{C}$ exposed to the damaging dose of $60 \mathrm{dpa}$ which is one order less as compared to a similar Kh16N15M3T1 steel without titanium or with $0.3 \mathrm{wt} \%$ of titanium.
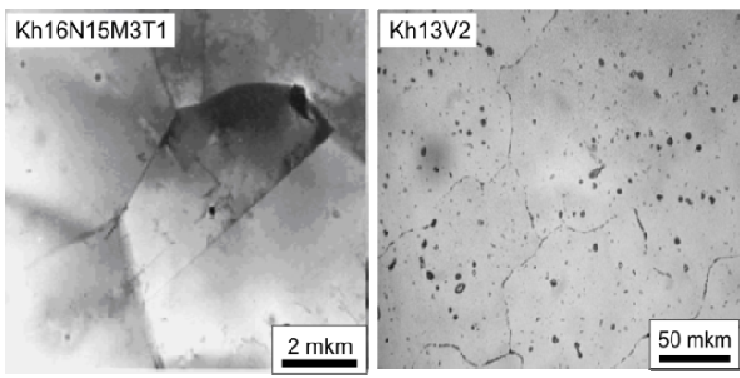

Fig. 1. Kh16N15M3T1 and Kh13V2 microstructure after quenching at $1100^{\circ} \mathrm{C}$.

Kh13B2 steel contains the elements listed in table 2, it is the reactor material with lower induced activity after neutron irradiation.

Table 2. Kh13V2 steel chemical composition.

\begin{tabular}{|c|c|c|c|c|c|c|c|c|}
\hline${ }_{12} \mathrm{C}$ & ${ }_{24} \mathrm{Cr}$ & ${ }_{74} \mathrm{~W}$ & ${ }_{25} \mathrm{Mn}$ & ${ }_{14} \mathrm{Si}$ & ${ }_{23} \mathrm{~V}$ & ${ }_{41} \mathrm{Nb}$ & ${ }_{22} \mathrm{Ti}$ & ${ }_{39} \mathrm{Y}$ \\
\hline 0.08 & 12.1 & 2.1 & 0.27 & 0.43 & 0.01 & 0.19 & 0.65 & 0.33 \\
\hline
\end{tabular}

Fig. 1 shows the structure of Kh13V2 specimen quenched at $1100{ }^{\circ} \mathrm{C}$. Kh13V2 steel, in terms of its structure, consists of ferritic grains sized 100-150 $\mu \mathrm{m}$ with curved interfaces (electron microdiffraction proves the presence of the ferritic grains with BCC lattice). The second-phase dispersion particles are located within the grains and at the grain boundaries.

\section{Basic data and experimental setup}

\footnotetext{
${ }^{\mathrm{a}}$ Corresponding author: avpavlenko@vniitf.ru
} 
$0.5,1,2,4$, and $8 \mathrm{~mm}$ thick samples were made of $34 \mathrm{~mm}$ diameter rods.

The ultrasonic technique was used to measure the sound velocity: for Kh16N15M3T1 steel, longitudinal $\mathrm{c}_{\mathrm{l}}=5731 \pm 10 \mathrm{~m} / \mathrm{s}$ and transverse $\mathrm{c}_{\mathrm{s}}=3037 \pm 2 \mathrm{~m} / \mathrm{s}$, calculated volume sound velocity was equal to $\mathrm{c}_{\mathrm{o}}=4.53 \mathrm{~km} / \mathrm{s}$; for Kh13V2 steel, $-\mathrm{c}_{\mathrm{l}}=5972 \pm 10 \mathrm{~m} / \mathrm{s}$, $\mathrm{c}_{\mathrm{s}}=3140 \pm 5 \mathrm{~m} / \mathrm{s}$, the volume sound velocity made $4.57 \mathrm{~km} / \mathrm{s}$. For Kh16N15M3T1 and Kh13V2 steels, the material density equaled to 7.65 and $7.95 \mathrm{~g} / \mathrm{cm} 3$, respectively.

Most experiments were carried out using the "symmetric shock" pattern, i.e. the impactor and the specimen were made of the same material. $12 \mathrm{Kh} 18 \mathrm{~N} 10 \mathrm{~T}$ steel impactors were used in few tests.

A light-gas gun with $44 \mathrm{~mm}$ diameter launch tube was used to perform the experiments. Fig. 2 shows schematics of the experimental set up. The specimen free surface velocity was measured by VISAR and PDV interferometers, velocity and nonflatness of the impactor-specimen collision $V_{0}$ was measured by the contact-sensor method.

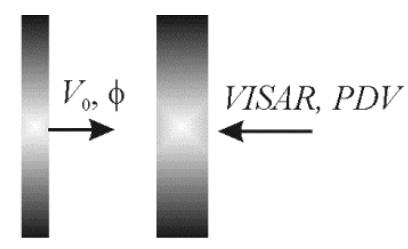

Impactor Sample

Fig. 2. Schematics of the experimental setup.

\section{Experimental results}

Fig. 3 and fig. 4 shows the measured velocity profiles.

The experimental evidence covers the loading rate ranging from 200 to $1500 \mathrm{~m} / \mathrm{s}$.

Fig. 5 and fig. 6 summarizes the collected data and shows the empirical spallation strength dependencies for steels under study. The strain rate realized in the rarefaction wave range from $4 \cdot 10^{4}$ to $3 \cdot 10^{6} \mathrm{~s}^{-1}$.

The resulting spallation strength data associated with Kh16N15M3T steel can be fitted by an empirical dependence on the deformation velocity in the rarefaction as follows: $\sigma_{w p}=0,26\left(\frac{v}{v}\right)^{0.21}$, for Kh13V2 in $\alpha$-phase a similar dependence takes the following form: $\sigma_{s p}=0.356\left(\frac{v}{v}\right)^{0.15}$. The type of dependence was chosen according to works [1, 2, 3] proving that the spallation strength-versus-deformation velocity relationship for a wide range of materials is a powerlaw dependence.

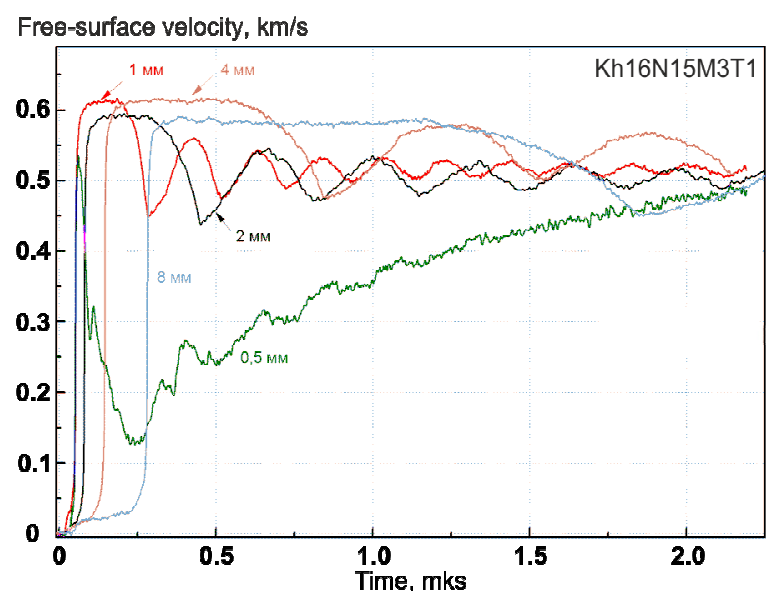

Fig. 3. The free-surface velocity profiles for Kh16N15M3T1 steel samples.

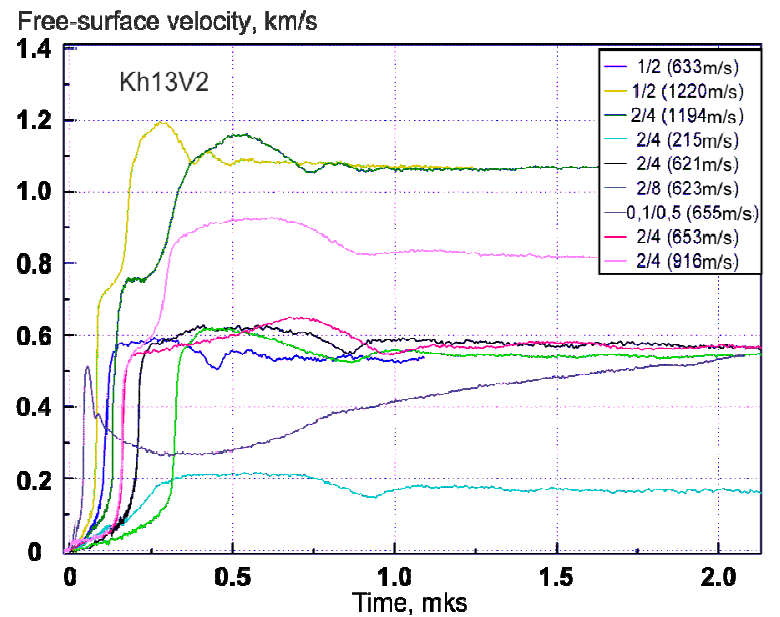

Fig. 4. The free-surface velocity profiles for Kh13V2 steel samples.

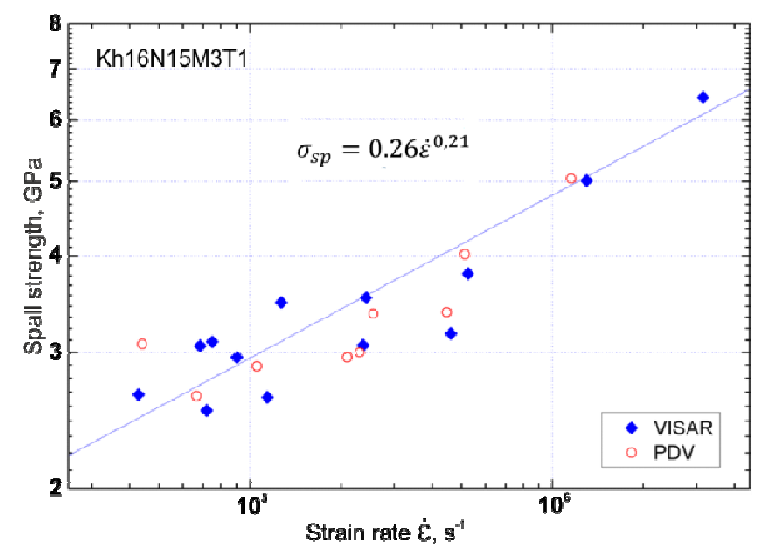

Fig. 5. Spallation strength-versus- strain rate relationships for Kh16N15M3T steel. 


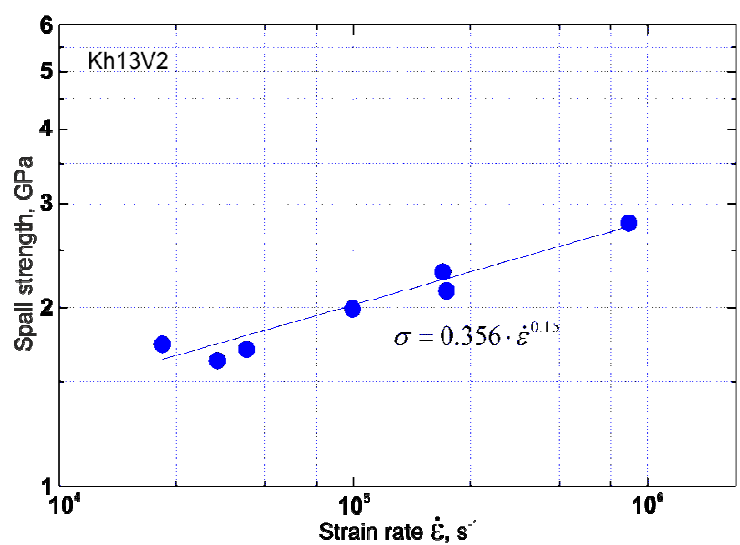

Fig. 6. Spallation strength-versus- strain rate relationships for Kh16N15M3T and Kh13V2 steels.

The temperature effect on changes in the material spallation strength in a wide temperature range is studied. The measured spallation strength of Kh16N15M3T1 steel sample heated to $914{ }^{\circ} \mathrm{C}$ was (2.07 \pm 0.07$) \mathrm{GPa}$, the spallation strength values of cooled Kh16N15M3T1 steel samples were $(3.17 \pm 0.08)$ and $(3.19 \pm 0.08) \mathrm{GPa}$. The spallation strength values were obtained disregarding change in the sound density and velocity in heated and cooled steel specimens.

Fig. 7 summarizes the measured spallation strengthversus-temperature relationship for Kh16N15M3T1 steel samples 4-8-mm thick. Spallation strength of the steel samples cooled to -90 and $-80{ }^{\circ} \mathrm{C}$ equals to $\sim 3.2 \mathrm{GPa}$; under normal temperature the observed values ranged from 2.9 to $3.1 \mathrm{GPa}$ and one can clearly see a minor trend towards reduction of the spallation strength up to $2.6-2.8 \mathrm{GPa}$. Heating to $\sim 900{ }^{\circ} \mathrm{C}$ leads to decrease in Kh16N15M3T1 steel spallation strength up to $\sim 2.1 \mathrm{GPa}$.

Kh13V2 was studied at normal and elevated to $\sim 500{ }^{\circ} \mathrm{C}$ temperature. The measured results show that at the specimen normal temperature the phase precursor amplitude equals to $13.3 \mathrm{GPa}$. The sample temperature elevated to $\sim 500{ }^{\circ} \mathrm{C}$ leads to significant decay of the phase precursor to $10.2 \mathrm{GPa}$.

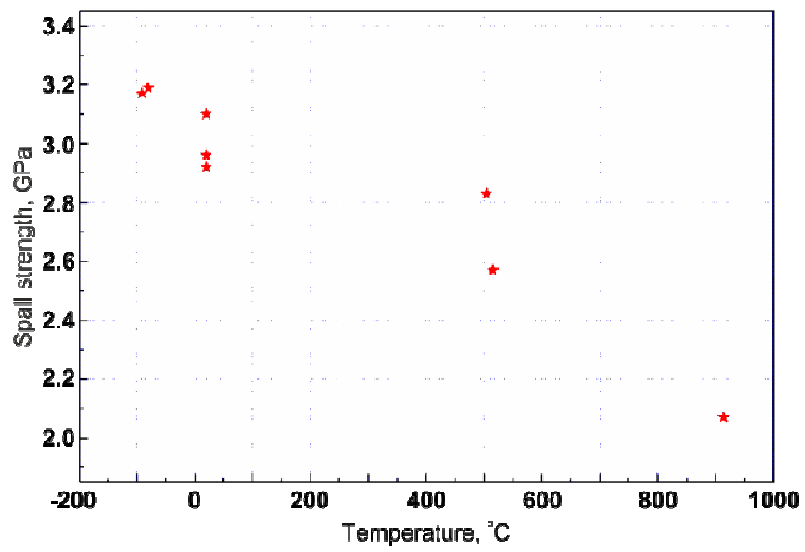

Fig. 7. Spallation strength-versus-temperature dependence for Kh16N15M3T1 steel. The strain rate is $\sim 10^{5} \mathrm{~s}^{-1}$.

The specimens loaded by shock waves with the amplitude $\sim 22 \mathrm{GPa}$ are heated for $60^{\circ} \mathrm{C}$ or less so the spallation strength values were calculated as if the material was at normal conditions. Fig. 8 shows the summarized diagram of the spallation strength-versusdeformation velocity within the experimental error.

The results of this investigation demonstrate that at the temperatures ranging from 23 to $500{ }^{\circ} \mathrm{C}$ the observed spallation strength values can be described by a uniform deformation velocity dependence: $a_{s p}=0.356\left(\frac{v}{W}\right)^{0.15}$.

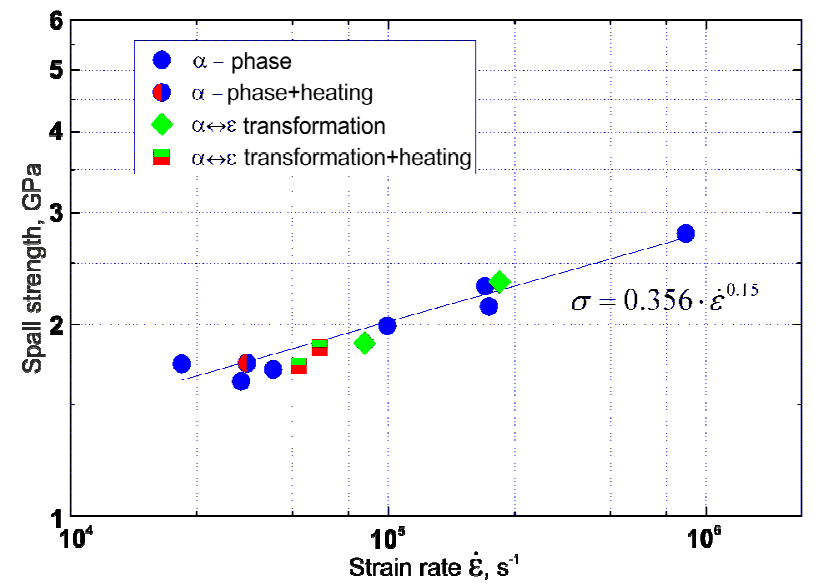

Fig. 8. Kh13V2 steel spallation strength-versus- deformation velocity. The test data was combined with the samples changed in the course of $\alpha \rightarrow \varepsilon$ transition, as well as with the ones heated to $500{ }^{\circ} \mathrm{C}$.

For Kh16N15M3T1 steel, the elastic precursors were registered on the stress-wave profiles. The experimental results were used to estimate relaxation of elastic precursor amplitude versus thickness of specimens (Fig. 9). The following dependences describe the measured data: $\sigma_{h}=0.75 \cdot\left(h / h_{o}\right)^{-0.38}$ for the tests at normal conditions and $\sigma_{h}=0.69 \cdot\left(h / h_{o}\right)^{-0.47}$ for the tests with samples initially heated at $\sim 500^{\circ} \mathrm{C}$.

The type of relationships was chosen according to works [1-3].

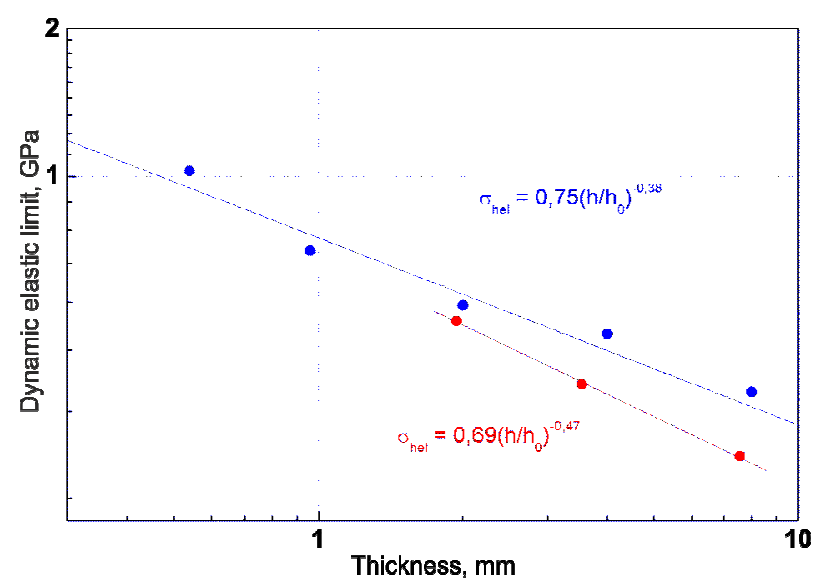

Fig. 9. Dynamic elastic limit relaxation versus the distance covered for Kh16N15M3T1 steel specimen.

\section{Metallography analysis}

Metallography analysis was carried out with the 
recovered samples to study the deformation mechanism and the structural changes due to shock-wave loading.

Increase in microstrength along the entire specimen cross-section of Kh16N15M3T1 steel (from 2.5 to 3.0$3.3 \mathrm{GPa}$ ) was observed with the shock-wave loading applied at the rate of $650 \mathrm{~m} / \mathrm{s}$ and, particularly, at $827 \mathrm{~m} / \mathrm{s}$. Microhardness along Kh16N15M3T1 steel specimen cross-section was slightly changed at the rate of about $200 \mathrm{~m} / \mathrm{s}$. However, the maximum microhardness (4.1-4.3 GPa) was observed in the central segments of all the shocked specimens near the spallation strength surface, which is attributed to steel hardening under local plastic deformation (before damage) in this zone.

It is determined that high-rate plastic deformation at $-90{ }^{\circ} \mathrm{C}$ and at normal temperature in Kh16N15M3T1 austenitic steel does not lead to formation of the martensitic phase with BCC and HCP lattices.

Deformation at the loading rate of $211 \mathrm{~m} / \mathrm{s}$ at $23{ }^{\circ} \mathrm{C}$ is due to dislocation sliding. Drop of the specimen temperature to $-90{ }^{\circ} \mathrm{C}$ and higher loading velocity contribute to formation of twins along with dislocation sliding. The applied shock-wave velocity increased from 211 to 650 and $827 \mathrm{~m} / \mathrm{s}$, leads to growth of dislocation density over the cross-section of the samples loaded to $1.8 \cdot 10^{10}, 2.5 \cdot 10^{10}, 6.4 \cdot 10^{10} \mathrm{~cm}^{-2}$. The steel strength properties improve under high-rate deformation due to formation of dislocations and deformation twins.

In the course of tests, Kh13V2 steel specimens were not only damaged by the spallation fracture mechanism but also cracked into separate pieces. The specimens with the spallation fracture that were tested at normal and elevated temperatures could be recovered in the near-primary form only at the loading level of about $4 \mathrm{GPa}$, which is equivalent to the loading velocity of $\sim 215 \mathrm{~m} / \mathrm{s}$.

The electron microscope investigation of Kh13V2 fine-structure samples exposed to shock waves at the rate of $215 \mathrm{~m} / \mathrm{s}$ and at 25 and $509^{\circ} \mathrm{C}$ show that the ferritic matrix with BCC lattice is recovered under such exposure. Changes are only observed in the dislocation structure of the steel under study. The electron microscopic analysis of Kh13V2 revealed no traces of $\varepsilon$-phase which could have formed and removed as a result of reversible $\alpha \rightarrow \varepsilon \rightarrow \alpha$ transition under shock wave. The sample structure demonstrates high density of dislocations due to shock pulses when the sample was loaded at $25^{\circ} \mathrm{C}$. The linear defects are arranged to form the network-cellular dislocation structure. The cell boundaries are wide and represent the dislocation clusters. The cell is about $400-\mathrm{nm}$ wide and 1200-nm long.

When the temperature of the shock pulse action increases to $509{ }^{\circ} \mathrm{C}$, a similar network-cellular structure is formed. However, the prevailing cell size becomes less: 200-300 $\mathrm{nm}$ widthway and 500-600 nm length way. Coarse carbide particles resembling $\mathrm{Me}_{23} \mathrm{C}_{6}$ are recovered in the steel structure influenced by the shock pulses.

\section{Conclusion}

Kh16N15M3T1 and Kh13V2 steels being promising candidates for nuclear power engineering are studied.

The investigations were carried out in a wide range of the deformation velocities realized in the rarefaction wave (from $4 \cdot 10^{4}$ to $3 \cdot 10^{6} \mathrm{~s}^{-1}$ ) and in $0.05-1 \mu \mathrm{s}$ duration range of the shock loading pulses.

Velocity-versus-temperature relationships for steel resistance to deformation and damage are obtained.

For Kh16N15M3T1 steel, the experimental data is sufficiently approximated by an empirical relation: $\sigma_{s p}=0.26\left(\frac{v}{v}\right)^{0.21}$ heating the specimens to $\sim 500{ }^{\circ} \mathrm{C}$ leads to slight decrease in the spallation strength. In addition, dependences of the dynamic elastic limit relaxation in the specimens at normal: $\sigma_{h}=0.75 \cdot\left(h / h_{o}\right)^{-0.38}$ and elevated to $\sim 500 \quad{ }^{\circ} \mathrm{C}$ temperatures: $\sigma_{h}=0.69 \cdot\left(h / h_{o}\right)^{-0.47}$ are obtained.

Structural and phase transitions in shocked steels were studied and hardness changes in quenched austenitic Kh16N15M3T1 steel were analyzed.

The test results for Kh13V2 steel demonstrate that at temperatures ranging from 23 to $500{ }^{\circ} \mathrm{C}$ the observed spallation strength values can be described by a unified deformation velocity dependence:

$$
\sigma_{s p}=0.356\left(\frac{N}{v}\right)^{0.15} \text {. }
$$

The electron microscopic analysis of Kh13V2 steel revealed no traces of $\varepsilon$-phase which might have formed and vanished in the course of reversible $\alpha \rightarrow \varepsilon \rightarrow \alpha$ transition under a shock wave. High density of dislocations is observed in the specimen structure under the shock pulse action when the specimen was loaded at $25^{\circ} \mathrm{C}$. The linear defects are arranged to form the network-cellular dislocation structure. The temperature of the shock pulse action elevated to $500{ }^{\circ} \mathrm{C}$ leads to formation of a similar network-cellular dislocation structure but the prevailing cell size becomes almost twice less.

\section{References}

1. G. Kanel, V. Fortov, S. Razorenov, A. Utkin Shockwave phenomena in condensed media. M: Yanus-K, 408 (1996)

2. Utkin A.V. J. Appl. Mech. Tech. Phys., 4 (1993) [in Russian]

3. Utkin A.V. J. Appl. Mech. Tech. Phys., 6 (1992) [in Russian] 